\title{
DEFINING WORK-ZONES FOR RESOURCE ALLOCATION IN HONG KONG PUBLIC HOUSING PROJECT CONSTRUCTION USING HEURISTIC RULES AND OPERATIONS SIMULATION
}

\author{
SUBMITTED: July 2021 \\ REVISED: August 2021 \\ PUBLISHED: September 2021 \\ GUEST EDITORS: Francis Siu, Hung-Lin Chi, Hsi-hsien Wei \& Minkoo Kim \\ DOI: $10.36680 /$ j.itcon.2021.035
}

Zilu Lin, Ms., MPhil Student,

Department of Building and Real Estate, Faculty of Construction and Environment, The Hong Kong Polytechnic University

zi-lu.lin@connect.polyu.hk

Francis Siu, Dr.,

Assistant Professor, Corresponding Author,

Department of Building and Real Estate, Faculty of Construction and Environment,

The Hong Kong Polytechnic University

francis.siu@polyu.edu.hk

Daniel Chan, Dr.,

Associate Professor,

Department of Building and Real Estate, Faculty of Construction and Environment,

The Hong Kong Polytechnic University

daniel.w.m.chan@polyu.edu.hk

Daniel Lau, Mr., Director,

Able Engineering Company Limited

daniellau@ableeng.com.hk

SUMMARY: In Hong Kong, 6-day construction cycle always being used for constructing one typical floor of concrete building superstructure in a week. Work-zones are defined in the working platform for better allocation of limited resources. Once the work-zones are defined, the resources (labour, plant, materials) will be allocated to a specific zone to deliver the works on a particular day of the 6-day construction cycle. In practice, the definition of work-zone is dependent on the experience of project manager. Yet, there is no past research studied the evaluation of work-zone definition schemes. As such, in this research study, three heuristic rules are proposed for choosing better scheme of work-zone. The heuristic rules are based on (i) lengths of work-zone dividing line, (ii) fluctuations of daily duration, and (iii) utilisation rates of resource. To illustrate the steps of evaluating the scheme, an illustrative example is given. To illustrate the method application of the rules, a practical case study of constructing a 40-storey housing is given. The proposed rules were verified based on sensitivity analysis and expert validation. Conclusions are drawn by expressing the contributions and limitations of the proposed rules, followed by suggesting future research works.

KEYWORDS: work zone, 6-day cycle, simulation, work content, productivity

REFERENCE: Zilu Lin, Francis Siu, Daniel Chan, Daniel Lau (2021). Defining work-zones for resource allocation in Hong Kong public housing project construction using heuristic rules and operations simulation. Journal of Information Technology in Construction (ITcon), Special issue: 'CIB World Building Congress 2019: Constructing Smart Cities', Vol. 26, pg. 657-680, DOI: 10.36680/j.itcon.2021.035

COPYRIGHT: (C) 2021 The author(s). This is an open access article distributed under the terms of the Creative Commons Attribution 4.0 International (https://creativecommons.org/licenses/by/4.0/), which permits unrestricted use, distribution, and reproduction in any medium, provided the original work is properly cited. 


\section{INTRODUCTION}

In building construction, before constructing a concrete superstructure on site, work-zones are defined for facilitating worker allocation by project managers. Skilled workers are assigned to carry out specific construction works in a specific working area on site at particular time (i.e., specific weekdays in a week repetitively), meanwhile, the skilled workers are also assigned to work in all work-zones (i.e., swap the work-zones) such that all planned works are delivered. In practice, project managers are responsible for planning and scheduling the workflows of the skilled workers for delivering the concrete superstructure such that the project can be completed on time, while the foremen of the skilled workers of particular work trades are responsible for estimating the quantities of skilled workers required to deliver the site works of the projects constrained by the project delivery time planned by the project managers.

The work-zones are planned for better construction time and resource performance in building superstructure construction. The minimum number of work-zones is two. The larger the construction floor area of the building, the more the work-zones defined by the project managers. Since the skilled workers of particular trades carried out the site works in different days of a week, the work sequence of different work trades in a particular workzone must be followed in accordance with the technological relationships, while the work continuity of the worker trades in all work-zone must be guaranteed such that the skilled workers can be fully utilised. With the beauty of defining work-zones for resource allocation, when constructing different floors of a building, the same construction works can be performed repetitively in different work-zones by the same skilled workers thus reducing the idle time of limited workers.

In Hong Kong, "6-day cycle" is a commonly used construction method for constructing the concrete superstructures of the buildings. As coined by the name, one typical floor of the concrete superstructure must be delivered in one week (Leung and Tam, 2003). The building products of concrete walls, columns, beams, and slabs are constructed. The work activities are mainly placing formworks, fixing reinforcements, and pouring concrete. Three corresponding critical work trades are mainly form workers, bar benders, and concreters. The work activities in the defined work-zones are sequenced such that the technological constraints are satisfied.

For illustrating the importance and impact of work-zone definitions, Tab. 1, 2, 3, and 4 contrast the difference of the activity execution plan and resource allocation plan if work-zones are being defined and not being defined. Tab. 1 shows the activity execution plan if no work-zone being defined. Tab. 2 shows the activity execution plan if two work-zones being defined. Tab. 3 shows the resource allocation plan of these three resources if no workzone being defined. Tab. 4 shows the resource allocation plan of these three resources if two work-zones being defined. With the work-zones being defined, the idle time of the workers can be obviously reduced (e.g., by two days for form workers and bar benders, and one day for concreters).

Nonetheless, the definition of work-zones, work activities, and workflow sequence are always based on the site experience of project manager without any established or researched heuristic rules. As illustrated, the time and resource schedules are closely related to the work-zone definitions. The project manager always welcomes any work-zone definitions which causes less fluctuations on the daily site working hours. That means a worker deployment schedule with 8 hours per day and 5 days per week is preferable than the one with 20 hours per day and 2 days per week, in consideration of work feasibility and workers' morale.

This research explored and proposed a new set of heuristic rules for analytically evaluating the options of any available schemes of work-zone definitions given by the project managers in building superstructure construction from the perspectives of time scheduling and operation simulation. The overarching goal is to facilitate the project managers in evaluating the work-zone schemes such that the stability of daily duration can be improved (i.e., the overtime of the workers can be reduced) and the idle time of the limited skilled workers can be reduced. In particular, the research scope is confined to the allocation of skilled workers for delivering the work activities in building superstructure construction using 6-day cycle.

The rest of this paper is organised as follows: the literature studies are reviewed to highlight the research works in repetitive scheduling in the context of graphical scheduling methods, mathematical modelling methods, and operation simulation methods. Next, three heuristic rules for evaluating the work-zone schemes for superstructure construction are proposed and explained. Then, a practical case study on the superstructure construction of a 40storey housing project was conducted to illustrate and validate the method application of the proposed heuristic rules in determining a better scheme of work-zones. The conclusions are drawn by summarising the academic and 
practical contributions of this research study and giving the limitations of the proposed method for any possible research opportunities in the future.

TAB. 1: Typical 6-day construction cycle without defining work-zone

\begin{tabular}{|c|l|}
\hline Day in a week & \multicolumn{1}{|c|}{ Construction activities (without defining work-zone) } \\
\hline 1 & - Formwork installation (slab) \\
\hline 2 & - Reinforcement fixing (slab) \\
\hline 3 & - Concrete pouring (slab) \\
\hline 4 & - Reinforcement fixing (wall) \\
\hline 5 & - Formwork installation (wall) \\
\hline 6 & - Concrete pouring (wall) \\
\hline
\end{tabular}

TAB. 2: Typical 6-day construction cycle with two defined work-zones

\begin{tabular}{|c|c|c|}
\hline Day in a week & Construction activities (Zone A) & Construction activities (Zone B) \\
\hline 1 & $\begin{array}{l}\text { - Reinforcement fixing (slab) } \\
\text { - Formwork installation (slab) }\end{array}$ & $\begin{array}{l}\text { - Reinforcement fixing (wall) } \\
\text { - Formwork installation (wall) }\end{array}$ \\
\hline 2 & $\begin{array}{l}\text { - Reinforcement fixing (slab) } \\
\text { - Formwork installation (slab) }\end{array}$ & $\begin{array}{l}\text { - Reinforcement fixing (wall) } \\
\text { - Formwork installation (wall) }\end{array}$ \\
\hline 3 & - Concrete pouring (slab) & - Concrete pouring (wall) \\
\hline 4 & $\begin{array}{l}\text { - Reinforcement fixing (wall) } \\
\text { - Formwork installation (wall) }\end{array}$ & $\begin{array}{l}\text { - Reinforcement fixing (slab) } \\
\text { - Formwork installation (slab) }\end{array}$ \\
\hline 5 & $\begin{array}{l}\text { - Reinforcement fixing(wall) } \\
\text { - Formwork installation (wall) }\end{array}$ & $\begin{array}{l}\text { - Reinforcement fixing (slab) } \\
\text { - Formwork installation (slab) }\end{array}$ \\
\hline 6 & - Concrete pouring (wall) & - Concrete pouring (slab) \\
\hline
\end{tabular}

TAB. 3: Resource allocation without defining work-zone

\begin{tabular}{|l|c|c|c|c|c|c|}
\hline \multicolumn{1}{|c|}{ Resource } & Day 1 & Day 2 & Day 3 & Day 4 & Day 5 & Day 6 \\
\hline Form workers & $\checkmark$ & & & & $\checkmark$ & \\
\hline Bar benders & & $\checkmark$ & & $\checkmark$ & & \\
\hline Concreters & & & $\checkmark$ & & & $\checkmark$ \\
\hline
\end{tabular}

TAB. 4: Resource allocation with two defined work-zones

\begin{tabular}{|l|c|c|c|c|c|c|}
\hline \multicolumn{1}{|c|}{ Resource } & Day 1 & Day 2 & Day 3 & Day 4 & Day 5 & Day 6 \\
\hline Form workers & $\checkmark$ & $\checkmark$ & & $\checkmark$ & $\checkmark$ & \\
\hline Bar benders & $\checkmark$ & $\checkmark$ & & $\checkmark$ & $\checkmark$ & \\
\hline Concreters & & & $\checkmark$ & & & $\checkmark$ \\
\hline
\end{tabular}




\section{LITERATURE REVIEW}

Repetitive works can be defined in construction projects (e.g., high-rise housings, airport runways, highways, bridges, pipelines, tunnels, and railways). In high-rise housing projects, the construction activities for constructing one floor are known as the repetitive works, because the structures of the concrete elements are identical as per each floor, given by the engineering drawings. In past decades, renowned researchers proposed methods for scheduling repetitive works. The scheduling methods are based on graphical scheduling techniques, mathematical modelling techniques, and operations simulation techniques.

\subsection{Graphical approach}

Graphical scheduling techniques characterise graphical schedules for visualising construction process with repetitive nature. The line of balance (LOB) technique, which was originated by the Goodyear Company in the early 1940s, is well-known for graphically scheduling the repetitive projects in consideration of the production rate of resources and the continuity of resource utilisation. The LOB schedules show the production rate and activity duration graphically (Suhail and Neale, 1994).

The researchers worked on improving the LOB algorithms used for scheduling construction projects, given the advancement of the computer optimisation performance. Damci et al. (2013) proposed a genetic algorithm-based resource leveling model for scheduling LOB projects. This avoids the productivity decline when leveling resources in LOB model. Hegazy et al. (2014) focused on the importance of tracking and controlling the activities given in the LOB schedules. They discovered that the time and cost can be reduced if the daily progress and critical path were updated during construction. Zhang et al. (2014) enhanced LOB model by integrated it with learning curve and a mechanism of resource allocation. This model works well in minimize the total resource usage of a project with the constraints of work continuity and dealing of each activity. Agrama $(2014,2015)$ proposed an essence LOB-based scheduling technique for non-identical multi-story building projects. This technique characterises the graphical schedules constrained by the logical relationships and resource continuities. Saad et al. (2017) empowered the LOB scheduling technique by genetic algorithm. The technique was implemented in batching and pull-production systems. The production cost and time can be reduced.

In addition, researchers emphasised on the integration of the LOB and technologies. For instance, Arditi et al. (2002) proposed a computerized system that combined LOB technology with several knowledge sources of precedence relationship among activities embedded in an expert system. Tokdemir et al. (2019) combined LOB method and Monte Carlo simulation, to estimate the risk of delay, monitor the changes in resource utilisation, and formulate the risk mitigation strategies. Tomar and Bansal (2019) merged LOB and CPM for scheduling linear projects. Also, they used GIS and BIM technologies to model the site surroundings and building components which may generate the constraints for scheduling the linear projects.

\subsection{Mathematical approach}

Mathematical approaches were proposed to materialise and optimise the repetitive schedules using mathematics. The commonly seen objective functions of these models are to minimise the project time and cost. The technological constraints are expressed to guarantee that the activities must follow the technological sequence. The resource constraints are expressed to guarantee that the resource workflows must be continued as per the work cycles.

Linear programming is a mathematical method aimed to achieve the best outcome with constraints which are represented by mathematical equations. For example, Lopez et al. (2010) proposed a linear programming model for scheduling building projects. Undesirable situations were given in a case study. Cho et al. $(2010 ; 2011)$ proposed an integrated schedule and cost mathematical models for repetitive projects with consideration of both the idle time of labor resources and the use of equipment resource. Case study of high-rise buildings was presented.

Besides, Lucko (2009) proposed a mathematical model of repetitive activities based on singularity functions firstly, which minimised the overall project duration make span under consideration of all constraints from time and buffers. Su et al. (2016) proposed a method that combine linear scheduling with LOB and singularity function, which considered the crew arrangement apart from activity. Biruk and Rzepecki (2019) took into account the impact of worker learning and forgetting effect towards the activity duration in a linear scheduling model. Better estimates of project time were resulted. 


\subsection{Simulation approach}

Operations simulation imitates the workflows of construction operations in a project using computers. Researchers proved that computer simulation techniques are applicable for scheduling repetitive works. In particular, the processes in a work cycle are used as the simulation inputs for modelling the sequences of repetitive activities. The feasible solutions of schedules can be searched and guaranteed. Furthermore, the time uncertainties of delivering the repetitive activities in a project can be mimicked using the statistical distributions and random numbers. The researchers focused on the improvement of repetitive schedules using simulation-based optimisation and showcased the use of operations simulation techniques in repetitive scheduling applications.

Dhanasekar (2000) presented a simulation model based on queuing theory which optimised the size of resource constrained by project duration. Ioannou and Srisuwanrat (2006) proposed an activity-based simulation system. The sequence step algorithm was used. This system scheduled probabilistic repetitive projects with uncertain activity durations while ensuring continuous resource utilisation. Shaheen et al. (2009) integrated discrete event simulation with fuzzy expert systems. This method minimised the subjectivity in scheduling building projects. Sadeghi et al. (2015) simulated the subjective uncertainties of planned activity duration. Rzepecki and Biruk (2018) simulated the schedules that improved crew work continuity constrained by activity duration and learning curve. Tokdemir et al. (2019) proposed a simulation method using Monte Carlo simulation and quantified the delay risk in repetitive work.

Some researchers focused on the application of optimisation, such as genetic algorithm (Mitchell 1998), based on simulation. For example, Devi and Ananthanarayanan (2007) proposed a simulation-optimisation model based on genetic algorithm that could optimally assign resources to repetitive activities, contributing to minimise cost, duration and to maximise resource utilisation rate. Srisuwanrat et al. (2008) used simulation-optimisation for determining resource arrival dates, leading to reduced resource idle time when scheduling repetitive projects. Hegazy and Kamarah (2008) proposed a simulation-optimisation model based on genetic algorithm for scheduling high-rise building construction projects which emphasised on maintaining work continuity, factoring in the resource limits, optimum cost, and prespecified deadline.

\subsection{Motivations of proposing the heuristic rules for evaluating the schemes of work-zones}

In summary, thanks to the researchers, the graphical techniques, mathematical techniques, and simulation-based techniques were developed to improve the construction project schedules featuring repetitive works. The past research studies focused on the schedule improvement at project level, while a limited number of researchers focused on the improvement of detailed schedules at workface level (Liu et al. 2014; Siu et al. 2015; Siu 2016; Ho et al. 2020).

To the best of the authors' knowledge, the importance of defining the work-zones for worker allocation in concrete superstructure construction remains to be highlighted, and the formalisation of heuristic rules for selecting the best options of defining the work-zone are yet to be explored.

As such, the authors are motivated to study how the daily working duration and resource utilisation being impacted by the work-zone definitions in concrete superstructure construction using 6-day cycle. This research work is the first one in formulating the heuristic rules for evaluating the work-zone scheme in building construction. A practical case study is presented to illustrate and validate the applications of the proposed heuristic rules.

\section{PROPOSED METHODOLOGY}

\subsection{Proposed heuristic rules for defining work-zones}

The heuristic rules for the work-zone definition are proposed as followed.

1. Lengths of work-zone dividing lines

It is preferable to have a shorter work-zone dividing line.

2. Fluctuations of daily working durations

It is preferable to have lesser fluctuations of daily working duration in a cycle.

3. Utilisation rates of resources

It is preferable to have higher utilisation rates of resources in a cycle. 
The following sub-sections explain the above three heuristic rules. To illustrate the steps of using the heuristic rules for evaluating the work-zone definition schemes, a postulated example "Project A" is used.

In Project A, one typical floor of housing concrete superstructure is constructed. Project A consists of 8 work activities. The technological sequence of Project A is illustrated in Fig. 1. Two work-zones are defined as "Zone A" and "Zone B" (Refer to Bracket A and Bracket B in Fig. 1).

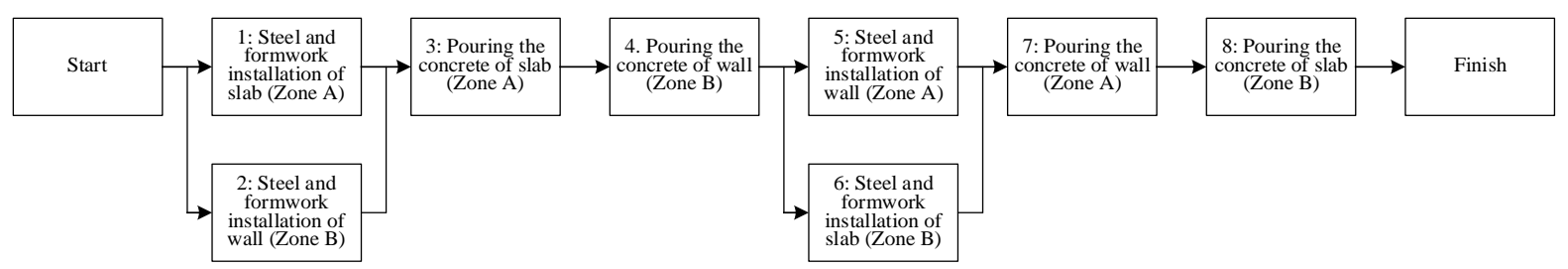

FIG. 1: Work sequence of constructing a typical floor of a housing concrete superstructure in Project A

\subsection{Lengths of work-zone dividing lines}

A line dividing the work-zones separates two work-zones on a working floor. The length of the dividing line is defined as its flat length in one floor of the building. When work activities swap among different work-zones, a shorter dividing line would be preferable, such that the labour, equipment, and material at workface level can be arranged, coordinated, and managed more easily during construction. Fig. 2 gives the plan view of the typical floor. Divided by the line, the two schemes of work-zones are shown.

There are two schemes for dividing work-zones. "Line A-B" in red colour is the dividing line for Scheme 1. "Line C-D" in blue colour is the one for Scheme 2. The length of these two lines can be determined using the construction work plan. The lengths of dividing lines are compared. The shortest dividing line is preferred. In this example, based on the first heuristic rule, the "Line A-B" is shorter than "Line C-D", so, Scheme 1 is better than Scheme 2.
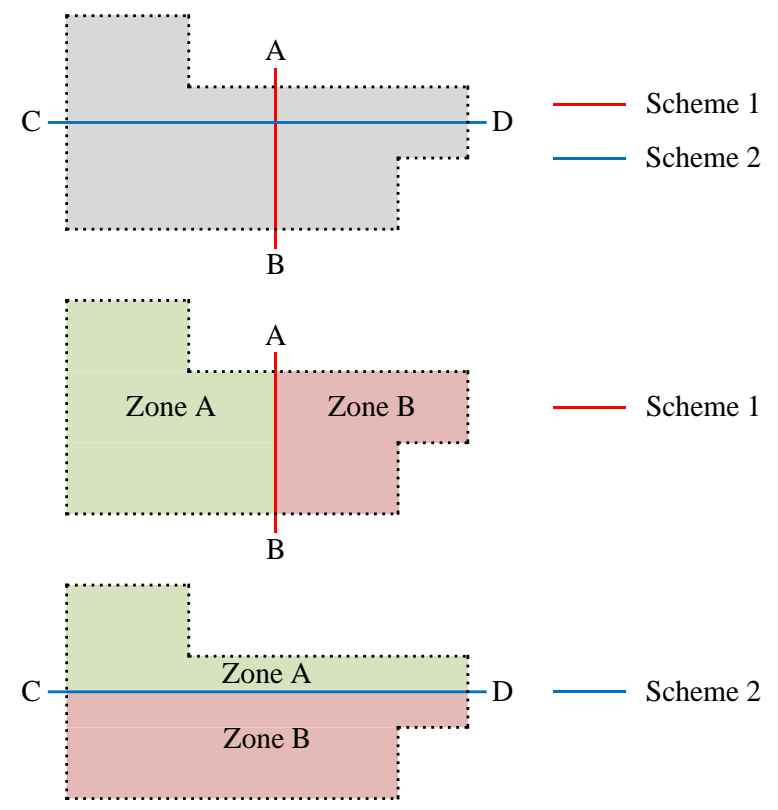

FIG. 2: Dividing line of work-zones

\subsection{Fluctuations of daily working durations}

Work content is the amount of work in an activity a worker delivered on site. The unit of measures depending on the activities, e.g., by volume, area, length, weight, or number. Notably, the amount of work content in different work-zones would be changed as per the dividing schemes. Since the work content varied, the activity duration and the daily working duration would be changed. The 2 nd heuristic rule recommended that the scheme with less fluctuations between the daily working durations among the days in a cycle is preferred. 


\section{Work content}

The work contents of (i) placing formwork, (ii) fixing reinforcement, and (iii) placing concrete are varied in accordance with work-zone definitions. These categories are commonly seen categories in concrete superstructure construction. The formwork is measured by the area of formwork. As the formwork is placed to hold the concrete in shape, the amount of formwork being placed is directly related to the concrete volumes in each work-zone. The amount of formwork is measured by area. The concrete work is defined by the volume of building elements made from concrete. The common concrete elements in a housing project are wall, slab, and beam. The work content of placing concrete in each work-zone varies as per the dividing schemes. The amount of concrete is measured by volume. The reinforcement work is defined by the weight of the reinforcement steel bar. The steel work content in work-zones would be different as per the schemes of work-zone definition. When determining the amount of steel in work-zones, it includes the steels used for the main building elements and the steels placed along the dividing line to provide additional strength along the line. The amount of reinforcement is measured by the weight. Nevertheless, apart from the above three main categories, the "other" category is given in association with the façade installation and electrical conduit installation. The work content of façade installation depends on the number of façades installed in each work-zone. The work content of installation of electrical conduits depends on the volume of slab.

To illustrate the change of reinforcement work content, an example based on a reinforced beam in Project A is used. Fig. 3 shows the change of reinforcement in the beam when divided by the line. Fig. 3(a) shows the reinforcement bars (in black colour) originally designed one. Fig. 3(b) shows the additional steel bar highlighted in brown colour when the beam is cut into two portions as separated by the dividing line (in red colour). The design formula of added steel length and corresponding added weight of the additional steel bar highlighted in brown colour are given as Equation (1) and Equation (2). The numbers of steel bar could be read from the engineering drawings and minimum tension lap length depends on the size of steel, types of steel, and concrete grade. For the above example, in accordance with the labels, the original number of the steel at the top is 11 , the diameter is 10 $\mathrm{mm}$, the centre-to-centre distance is $150 \mathrm{~mm}$. Therefore, the additional steel length and weight are calculated as $7,700 \mathrm{~mm}$ (Equation 3) and $4.7509 \mathrm{~kg}$ (Equation 4) respectively.

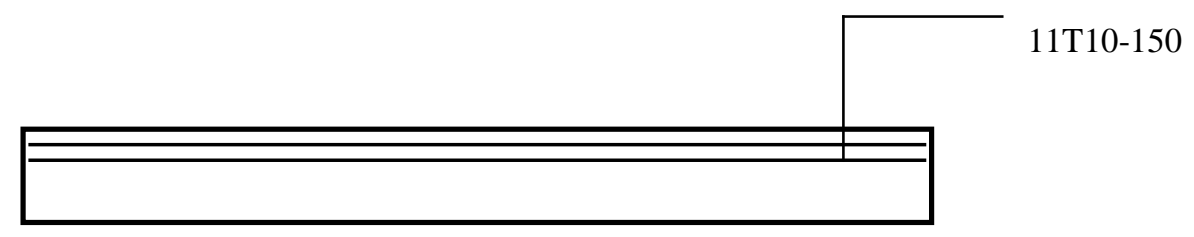

(a)

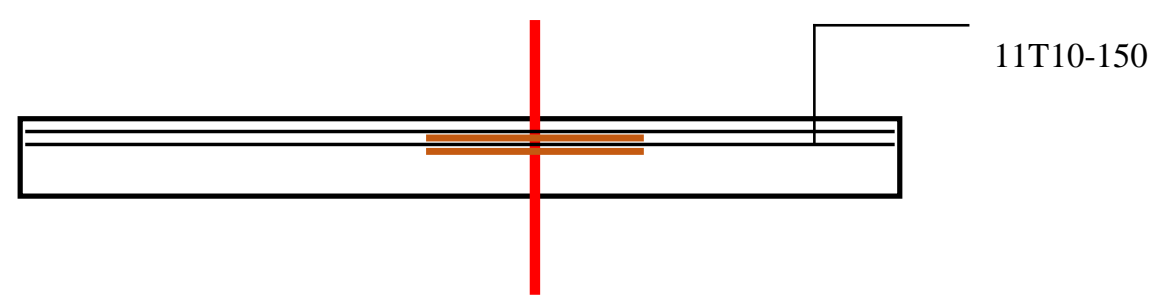

(b)

FIG. 3: Added steel around the dividing line

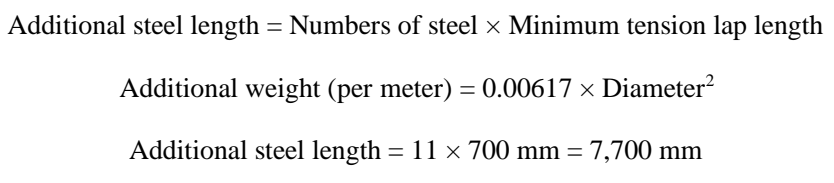




\section{$\underline{\text { Activity duration }}$}

As the work content of concrete, formwork, and reinforcement varies as per the scheme of defining the work-zone definitions, the durations of the activities under four main categories would be changed accordingly. The categories are "concrete-related", "reinforcement-related", "formwork-related", and "others". Tab. 5 lists the four categories and the activities under those categories.

TAB. 5: Activities under four main categories with its duration varied as per work-zone definitions

\begin{tabular}{|c|l|}
\hline \multicolumn{1}{|c|}{ Categories } & \multicolumn{1}{|c|}{ Activities } \\
\hline Formwork-related & Steel formwork installation \\
\hline \multirow{2}{*}{ Reinforcement-related } & Reinforcement connection fixing \\
\cline { 2 - 3 } & Reinforcement mesh fixing \\
\cline { 2 - 3 } & Reinforcement fixing \\
\cline { 2 - 2 } & Delivery of reinforcement by tower crane \\
\hline \multirow{2}{*}{ Concrete-related } & Concreting work \\
\cline { 2 - 3 } & Delivery of concrete by tower crane \\
\hline \multirow{2}{*}{ Others } & Façade installation \\
\hline & Electrical conduit installation \\
\hline
\end{tabular}

The changes of activity duration are proportionally varied to the changes of the work content for those activities under the "formwork-related", "reinforcement-related", and "concrete-related" categories. Nevertheless, the activity duration of "façade installation" and "electrical conduit installation" under the "others" category should be determined. For example, Tab. 6 gives the work content of reinforcement fixing for walls and slabs in Zone A and Zone B. The corresponding durations for delivering the work content are given.

\section{TAB. 6: Activity durations of reinforcement fixing for walls and slabs}

\begin{tabular}{|l|c|c|c|c|}
\hline & \multicolumn{2}{|c|}{ Work-zone definition (Scheme 1) } & \multicolumn{2}{c|}{ Work-zone definition (Scheme 2) } \\
\hline & Work content (kg) & Duration (hour) & Work content (kg) & Duration (hour) \\
\hline Reinforcement fixing of wall (A) & 40 & 2 & 35 & 1.5 \\
\hline Reinforcement fixing of wall (B) & 80 & 4 & 85 & 4 \\
\hline Reinforcement fixing of slab (A) & 70 & 2 & 60 & 2 \\
\hline Reinforcement fixing of slab (B) & 80 & 2 & 90 & 2 \\
\hline
\end{tabular}

\section{Daily working duration}

Daily working duration is the time planned for delivering the activities on a certain day in the 6-day cycle. Given the duration of activities as per the work-zone defining scheme, the daily duration could be determined. For instance, Fig. 4 shows the activity execution sequence of a day in Project A. There are two work activities in one day. The Node "Start" means the start of the day, and the Node "Finish" means the end of the day.

For each work-zone definition, given the work content and activity duration, the daily working durations in a 6day construction cycle can be therefore determined. For instance, based on the activity duration (dn) expressed in Tab. 7 for Scheme 1 and Scheme 2, the daily working durations (DWD1) are calculated as Equation (5) and Equation (6) respectively. Similarly, the durations of the other 5 days in the 6-day cycle for two schemes can be calculated as shown in Tab. 8. The fluctuation of DWDx is determined as the average of the difference between the two adjacent days as per Equation (7). The fluctuations of daily working durations (DWDx) are determined for each scheme. The fluctuations of daily working durations of Scheme 1 and Scheme 2 are 0.30 and 1.25 hours respectively. The work-zone definition scheme with minimum fluctuations of daily working durations is preferable. For Project A, Scheme 1 is thus preferable. 


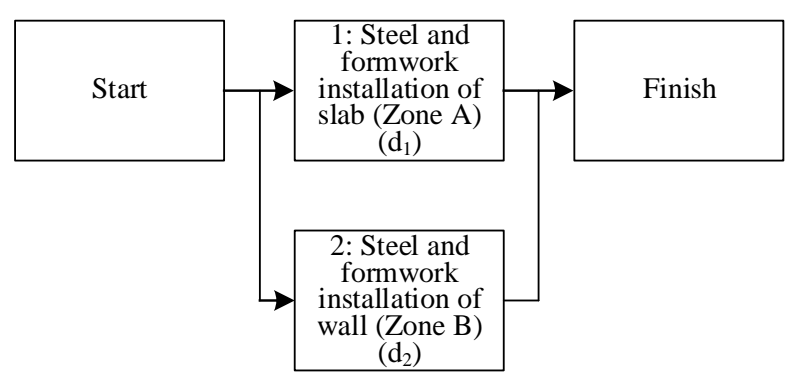

FIG. 4: Activities in one day

TAB. 7: Activity duration in one day

\begin{tabular}{|c|c|c|}
\hline Activity duration (hour) & $\mathrm{d}_{1}$ & $\mathrm{~d}_{2}$ \\
\hline Scheme 1 & 5.0 & 6.5 \\
\hline Scheme 2 & 4.5 & 7.5 \\
\hline
\end{tabular}

\begin{tabular}{|l|l|}
\hline Scheme 1: $D W D_{1}=\max \left\{\mathrm{d}_{1}, \mathrm{~d}_{2}\right\}=6.5$ (hours) & (5) \\
\hline Scheme 2: $\operatorname{DWD}_{1}=\max \left\{\mathrm{d}_{1}, \mathrm{~d}_{2}\right\}=7.5$ (hours) & (6) \\
\hline
\end{tabular}

TAB. 8 : Daily working durations

\begin{tabular}{|l|l|l|}
\hline Days in construction cycle & Scheme 1 & Scheme 2 \\
\hline Day 1 & 6.5 & 7.5 \\
\hline Day 2 & 7.0 & 6.0 \\
\hline Day 3 & 7.0 & 7.0 \\
\hline Day 4 & 6.5 & 8.0 \\
\hline Day 5 & 7.0 & 6.0 \\
\hline Day 6 & 7.0 & 8.0 \\
\hline
\end{tabular}

$$
\text { Fluctuation }=\frac{\sum_{\mathrm{n}=1}^{5}\left|\mathrm{DWD}_{\mathrm{n}+1}-\mathrm{DWD}_{\mathrm{n}}\right|}{5}
$$

\subsection{Utilisation rates of resources}

Resource utilisation rate $(\mathrm{R})$ is used to evaluate different scheme for work-zones. The resource utilisation rate is defined as the percentage of resource working time in total working time in one day. Based on the work sequence in Fig. 1, three main work trades (form worker, bar bender, concreter) required to deliver each activity are listed in Tab. 9. The resource utilisation rates of these three resources are calculated. The resource utilisation rates of these three resources in Scheme 1 are calculated (Equations 11, 12, 13). Similarly, the resource utilisation rates of these three resources in Scheme 2 are calculated (Equations 14, 15, 16). The average resource utilisation rates are $48.44 \%$ and $48.23 \%$ in Scheme 1 and Scheme 2 respectively. Work-zone division scheme with higher resource utilisation rate is more welcome among construction managers. As such, Scheme 1 should be selected. 
TAB. 9: Duration and resource of activities in Project A in Scheme 1

\begin{tabular}{|c|c|c|c|c|}
\hline Activity & Duration (hr) & Bar bender (nr) & Form worker (nr) & Concreter (nr) \\
\hline 1 & 5.0 & 1 & 1 & 1 \\
\hline 2 & 6.5 & & & 1 \\
\hline 3 & 7.0 & & & 1 \\
\hline 4 & 7.0 & 1 & 1 & 1 \\
\hline 5 & 5.0 & & & 1 \\
\hline 6 & 6.5 & & & 1 \\
\hline 7 & 7.0 & & & 1 \\
\hline
\end{tabular}

Scheme 1: Form worker : $\mathrm{R}=\frac{5+6.5+5+6.5}{5+50} \times 100 \%=56.09 \%$

Scheme 1: Bar bender : $\mathrm{R}=\frac{5+5}{44} \times 100 \%=23.39 \%$

Scheme 1: Concreter : $\mathrm{R}=\frac{7+747+7}{41} \times 100 \%=65.85 \%$

Scheme 2: Form worker : $\mathrm{R}=\frac{4.5+7.5+5+8}{42.5} \times 100 \%=58.82 \%$

Scheme 2: Bar bender : $\mathrm{R}=\frac{4.5+5}{42.5} \times 100 \%=22.35 \%$

Scheme 2: Concreter : $\mathrm{R}=\frac{6+7+6+8}{42.5} \times 100 \%=63.53 \%$

\subsection{Evaluation of work-zone definition schemes based on proposed heuristic rules}

In summary, the scheme for work-zone with shorter length of dividing line, less difference among daily working durations, and higher resource utilisation rates is preferred. Given the proposed heuristic rules, Scheme 1 is preferred.

TAB.10: Evaluation of work-zone definition schemes based on three heuristic rules

\begin{tabular}{|c|c|c|}
\hline No & Heuristic rules & Criterions \\
\hline 1 & Lengths of work-zone dividing lines & Shorter \\
\hline 2 & Fluctuations of daily duration & Less \\
\hline 3 & Utilisation rates of resources & Higher \\
\hline
\end{tabular}

\section{PRACTICAL CASE STUDY}

\subsection{Background}

The practical application of the proposed method is illustrated using a 40-storey building project. An overview, which captured by the BIM model, of the building product is shown in Fig. 5. It is a residential building located in Hong Kong with the area of 3,517 $\mathrm{m} 2$ and height of $122 \mathrm{~m}$. Floors $4 \mathrm{~F}$ to $39 \mathrm{~F}$ are typical floors with same structural design and layout. This project adapts 6-day construction cycle to construct 1 typical floor of a superstructure in 1 week. That means the construction works for constructing 4F are identical and repeated (from $4 \mathrm{~F}$ to $39 \mathrm{~F}$ ). The project planners divided a floor into two work-zones (Zone A and Zone B) as showed in Fig. 5. Four schemes for work-zone division were proposed (Fig. 6). The proposed heuristic rules were utilised to select the best work-zone scheme. Notably, operation simulation was used to determine resource utilisations. 


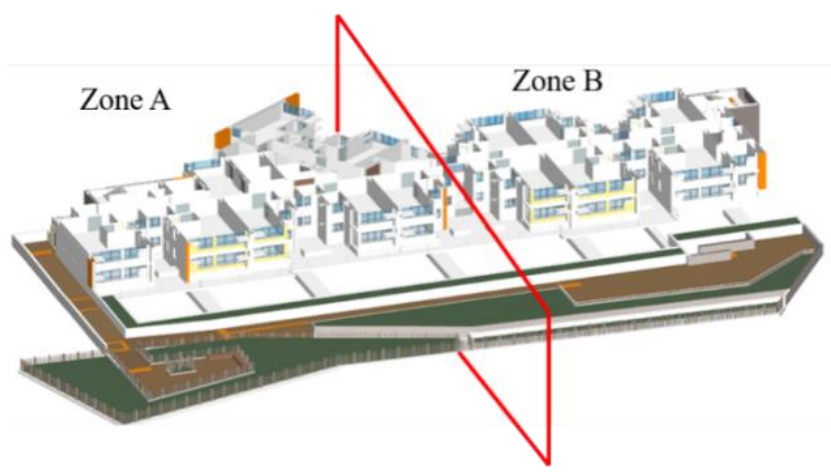

FIG. 5: Two work-zones

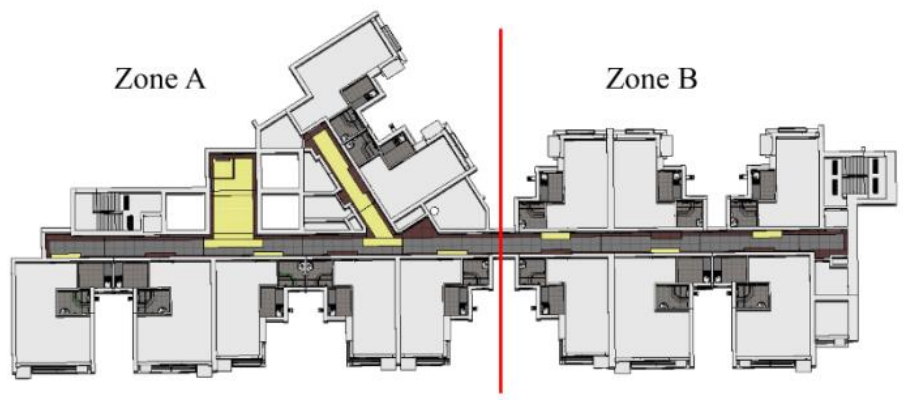

FIG. 6(a): Scheme 1 of work-zone definition

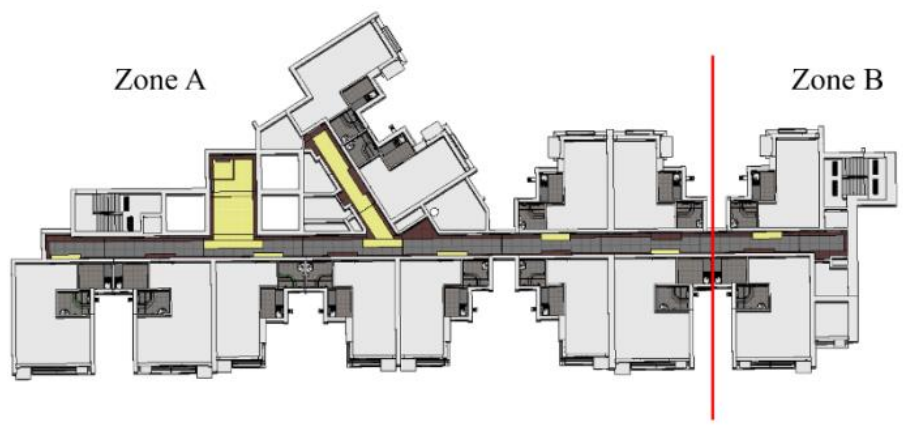

FIG. 6(b): Scheme 2 of work-zone definition

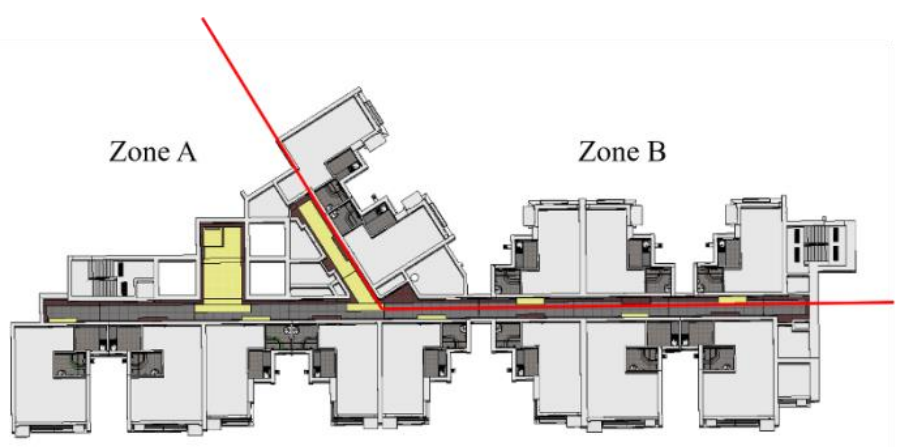

FIG. 6(c): Scheme 3 of work-zone definition 


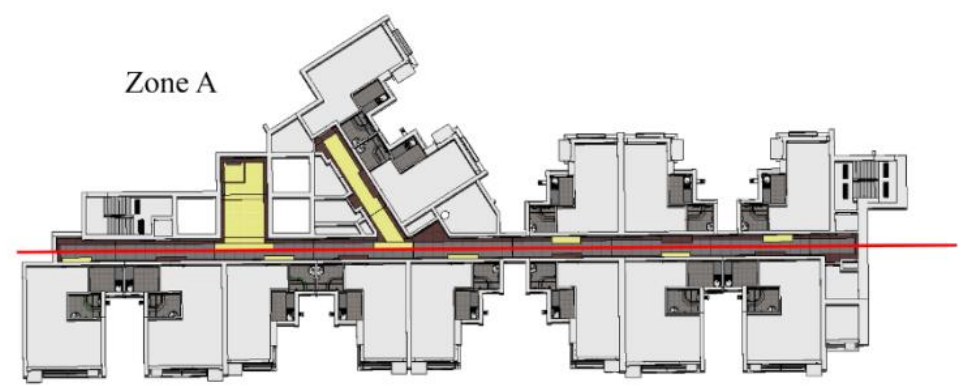

Zone B

FIG. 6(d): Scheme 4 of work-zone definition

\subsection{Typical work activity sequence and resource requirement}

The activity name, activity duration, precedence relationships and resource demand required of 40 work activities were defined as shown in Tab. 11. In this project, there are eight types of resources, consist of equipment ( 1 crane, 3 vibrators) and labour ( 4 form workers, 4 concreters, 14 bar benders, 1 crane operator, 5 electrical fitters, 5 laborers).

TAB. 11: Activity and resource definitions of the project

\begin{tabular}{|c|c|c|c|c|c|}
\hline Day & No & Activity & Duration (minutes) & Predecessor & Resource required[nr] \\
\hline 1 & 1 & Start of project & 0 & l & I \\
\hline 1 & 2 & Delivery of reinforcement (Zone A) & 44.125 & 1 & $\mathrm{CR}[1] ; \mathrm{CO}[1] ; \mathrm{BB}[14]$ \\
\hline 1 & 3 & Wall reinforcement mesh fixing (Zone A) & 1077.000 & 2 & $\mathrm{BB}[3]$ \\
\hline 1 & 4 & Installation of façade (Zone A) & 81.778 & 2 & $\mathrm{CR}[1] ; \mathrm{CO}[1] ; \mathrm{FW}[4]$ \\
\hline 1 & 5 & Wall reinforcement fixing (Zone A) & 430.981 & 3 & $\mathrm{BB}[14]$ \\
\hline 1 & 6 & Installation of façade (Zone B) & 94.900 & 4 & $\mathrm{CR}[1] ; \mathrm{CO}[1] ; \mathrm{FW}[4]$ \\
\hline 1 & 7 & Installation of electrical conduits (wall) (Zone A) & 284.000 & 5 & $\mathrm{EF}[5]$ \\
\hline 1 & 8 & Steel formwork installation (Zone A) & 458.125 & 6 & $\mathrm{CR}[1] ; \mathrm{CO}[1] ; \mathrm{FW}[4]$ \\
\hline 1 & 9 & Delivery of slab scaffold prop (Zone B) & 8.250 & 8 & $\mathrm{CR}[1] ; \mathrm{CO}[1] ; \mathrm{FW}[2]$ \\
\hline 1 & 10 & Delivery of pole shore (Zone B) & 2.250 & 9 & $\mathrm{CR}[1] ; \mathrm{CO}[1] ; \mathrm{FW}[2]$ \\
\hline 1 & 11 & Rebar lifting back (Zone A) & 11.375 & 10 & $\mathrm{CR}[1] ; \mathrm{CO}[1] ; \mathrm{BB}[2]$ \\
\hline 2 & 12 & Working platform lifting (Zone B) & 94.750 & 7,11 & $\mathrm{CR}[1] ; \mathrm{CO}[1] ; \mathrm{FW}[4]$ \\
\hline 2 & 13 & Installation of precast stairs (Zone B) & 13.556 & 12 & $\mathrm{CR}[1] ; \mathrm{CO}[1] ; \mathrm{FW}[3]$ \\
\hline 2 & 14 & Delivery of precast refuse chute (Zone B) & 6.125 & 13 & $\mathrm{CR}[1] ; \mathrm{CO}[1] ; \mathrm{FW}[3]$ \\
\hline 2 & 15 & Delivery of drywall (Zone B) & 28.875 & 14 & $\mathrm{CR}[1] ; \mathrm{CO}[1] ; \mathrm{FW}[2]$ \\
\hline 2 & 16 & Installation of semi-precast concrete slab (Zone B) & 100.000 & 15 & $\mathrm{CR}[1] ; \mathrm{CO}[1] ; \mathrm{FW}[4]$ \\
\hline 2 & 17 & Slab connection reinforcement fixing (Zone B) & 111.889 & 15 & $\mathrm{C}[2]$ \\
\hline 2 & 18 & Installation of electrical conduits on precast slab (Zone B) & 147.125 & 15 & $\mathrm{EF}[5]$ \\
\hline 2 & 19 & Installation of corridor electrical conduits (Zone B) & 372.143 & 18 & $\mathrm{EF}[4]$ \\
\hline 3 & 20 & Delivery of slab scaffold prop (Zone A) & 2.708 & $16,17,19$ & $\mathrm{FW}[2]$ \\
\hline
\end{tabular}




\begin{tabular}{|c|c|c|c|c|c|}
\hline Day & No & Activity & Duration (minutes) & Predecessor & Resource required[nr] \\
\hline 3 & 21 & Wall concrete pouring (Zone A) & 305.000 & 20 & $\mathrm{CR}[1] ; \mathrm{V}[3] ; \mathrm{CO}[1] ; \mathrm{C}[4] ; \mathrm{L}[5] ;$ \\
\hline 3 & 22 & Slab reinforcement mesh fixing (Zone B) & 183.856 & 21 & $\mathrm{BB}[2]$ \\
\hline 3 & 23 & Slab concrete pouring (Zone B) & 181.444 & 21,22 & $\mathrm{CR}[1] ; \mathrm{V}[1] ; \mathrm{CO}[1] ; \mathrm{C}[4] ; \mathrm{L}[5]$ \\
\hline 4 & 24 & Delivery of reinforcement (Zone B) & 45.000 & 23 & $\mathrm{CR}[1] ; \mathrm{CO}[1] ; \mathrm{BB}[14]$ \\
\hline 4 & 25 & Wall reinforcement mesh fixing (Zone B) & 126.500 & 24 & $\mathrm{BB}[3]$ \\
\hline 4 & 26 & Steel formwork installation (Zone B) & 470.571 & 24 & $\mathrm{CR}[1] ; \mathrm{CO}[1] ; \mathrm{FW}[4]$ \\
\hline 4 & 27 & Wall reinforcement fixing (Zone B) & 443.222 & 25 & $\mathrm{BB}[14]$ \\
\hline 4 & 28 & Delivery of slab scaffold prop (Zone A) & 2.708 & 26 & $\mathrm{CR}[1] ; \mathrm{CO}[1] ; \mathrm{FW}[2]$ \\
\hline 4 & 29 & Delivery of pole shore (Zone A) & 2.000 & 28 & $\mathrm{CR}[1] ; \mathrm{CO}[1] ; \mathrm{FW}[2]$ \\
\hline 4 & 30 & Installation of electrical conduits (wall) (Zone B) & 425.000 & 27 & $\mathrm{EF}[5]$ \\
\hline 5 & 31 & Working platform lifting (Zone A) & 60.125 & 29,30 & $\mathrm{CR}[1] ; \mathrm{CO}[1] ; \mathrm{FW}[4]$ \\
\hline 5 & 32 & Installation of precast stairs (Zone A) & 15.667 & 31 & $\mathrm{CR}[1] ; \mathrm{CO}[1] ; \mathrm{FW}[3]$ \\
\hline 5 & 33 & Delivery of drywall (Zone A) & 25.000 & 32 & $\mathrm{CR}[1] ; \mathrm{CO}[1] ; \mathrm{FW}[2]$ \\
\hline 5 & 34 & Installation of semi-precast concrete slab (Zone A) & 94.222 & 33 & $\mathrm{CR}[1] ; \mathrm{CO}[1] ; \mathrm{FW}[4]$ \\
\hline 5 & 35 & Slab connection reinforcement fixing (Zone A) & 76.778 & 33 & $\mathrm{BB}[2]$ \\
\hline 5 & 36 & Installation of electrical conduits on precast slab (Zone A) & 134.500 & 33 & $\mathrm{EF}[4]$ \\
\hline 5 & 37 & Installation of corridor electrical conduits (Zone A) & 151.625 & 36 & $\mathrm{EF}[4]$ \\
\hline 6 & 38 & Delivery of slab scaffold prop (Zone B) & 8.250 & $35,35,37$ & $\mathrm{CR}[1] ; \mathrm{CO}[1] ; \mathrm{FW}[2]$ \\
\hline 6 & 39 & Wall concrete pouring (Zone B) & 423.444 & 38 & $\mathrm{CR}[1] ; \mathrm{V}[2] ; \mathrm{CO}[1] ; \mathrm{C}[4] ; \mathrm{L}[5]$ \\
\hline 6 & 40 & Slab reinforcement mesh fixing (Zone A) & 130.667 & 38 & $\mathrm{BB}[2]$ \\
\hline 6 & 41 & Slab concrete pouring (Zone A) & 101.889 & 39,40 & $\mathrm{CR}[1] ; \mathrm{V}[1] ; \mathrm{CO}[1], \mathrm{C}[4] ; \mathrm{L}[5]$ \\
\hline 6 & 42 & Finish of project & 0 & 41 & I \\
\hline
\end{tabular}

(Note: $\mathrm{BB}=\mathrm{Bar}$ bender, $\mathrm{C}=$ Concreter, $\mathrm{CR}=\mathrm{Crane}, \mathrm{CO}=$ Crane operator, $\mathrm{EF}=$ Electrical fitter, $\mathrm{FW}=$ Form worker, $\mathrm{L}=\mathrm{Laborer}, \mathrm{V}=\mathrm{Vibrator}$ )

\subsection{Heuristic rule 1: Lengths of work-zone dividing lines}

The lengths of dividing line are 1.55, 3.38, 38.30049 .67 (unit: m) for Schemes 1, 2, 3, 4, respectively.

\subsection{Heuristic rule 2: Fluctuations of daily working durations}

Quantities of concrete, steel, and formwork

The detailed steps for extracting data from BIM model are illustrated. Figure 7 shows the quantity take-off function in Revit for extracting relevant information from the BIM model. In Revit, the "schedule/quantity" function is selected. Then, the building component (e.g., floor as slab) is selected, followed by extracting the data unit (e.g., volume) of this component. Then, the extracted data is exported to Excel spreadsheet. The missing data, repetitive information, and useless information (e.g., function, production stage, and repetitive types) were cleaned and removed. As the volume of concrete changes, the formwork would also vary with concrete. The area of formwork for four schemes is shown in Tab. 13. Based on construction drawings and minimum tension lap length (concrete grade is $\mathrm{C} 45$, and lap length factors are 2.0 for top steel and 1.4 for bottom steel), the weights of steel in two workzones were calculated in Tab. 14. 


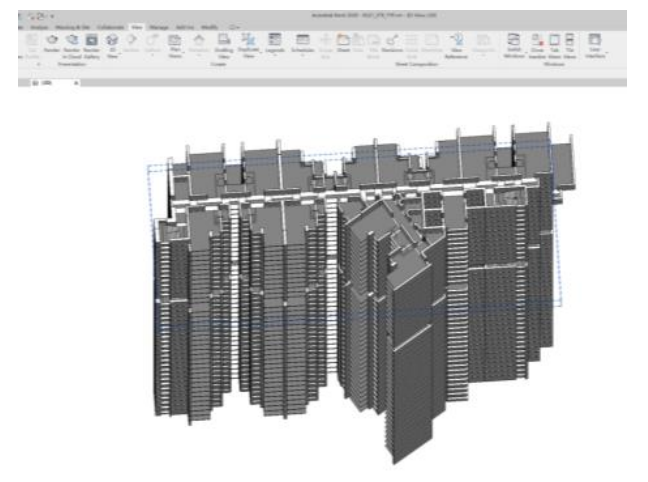

Step 1: Open BIM model in Revit and choose "schedule/quantity" button given in "view" tab

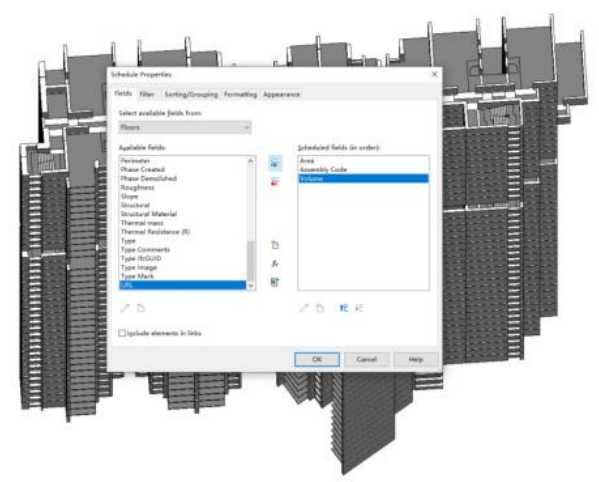

Step 3: Select data unit (e.g., volume)

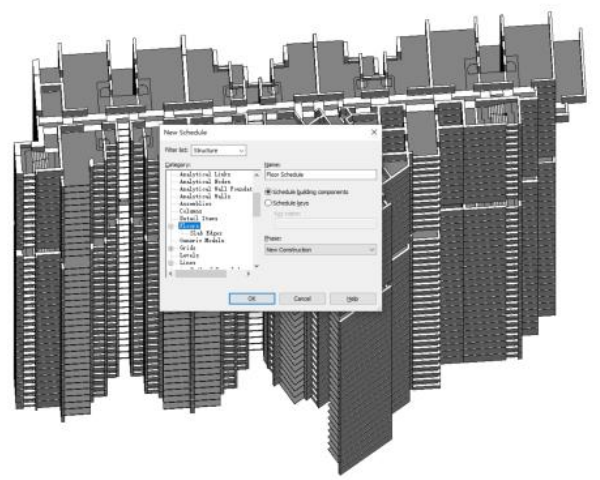

Step 2: Choose building component required (e.g., floor)

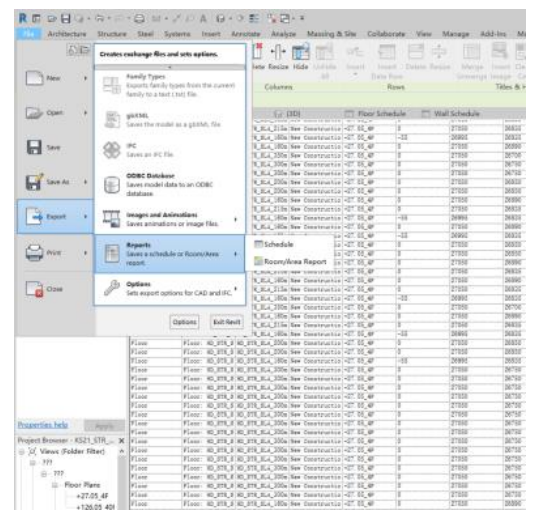

Step 4: Choose "report" in "export" for exporting data as Excel spreadsheet in Revit

FIG. 7: Data extraction from BIM model for work zone analysis

TAB. 12: Volume of concrete of four schemes

\begin{tabular}{|c|c|c|c|c|}
\hline Concrete $\left(\mathrm{m}^{3}\right)$ & Scheme 1 & Scheme 2 & Scheme 3 & Scheme 4 \\
\hline Zone A & 159.29 & 242.71 & 213.55 & 156.40 \\
\hline Zone B & 152.56 & 69.14 & 98.30 & 155.45 \\
\hline Difference & 6.72 & 173.56 & 115.26 & 0.95 \\
\hline
\end{tabular}

TAB. 13: Area of formwork of four schemes

\begin{tabular}{|c|c|c|c|c|}
\hline Formwork $\left(\mathrm{m}^{2}\right)$ & Scheme 1 & Scheme 2 & Scheme 3 & Scheme 4 \\
\hline Zone A & 666.62 & 1004.28 & 921.02 & 627.05 \\
\hline Zone B & 1050.86 & 507.26 & 641.29 & 1114.56 \\
\hline
\end{tabular}

TAB. 14: Weights of steel of four schemes

\begin{tabular}{|c|c|c|c|c|}
\hline Steel $(\mathrm{kg})$ & Scheme 1 & Scheme 2 & Scheme 3 & Scheme 4 \\
\hline Zone A & 11358.00 & 21958.93 & 19387.48 & 14268.76 \\
\hline Zone B & 16850.00 & 6258.88 & 8962.68 & 14182.83 \\
\hline
\end{tabular}




\section{Work activities and work durations}

Based on the abovementioned quantities, the work content of the activities associated with the concrete-related works (Tab. 15), reinforcement-related works (Tab. 16), concrete-related works (Tab. 17), and other works (Tab. 18) were determined. Given the work content of the activities, the activity durations associated with the concreterelated works (Tab. 19), reinforcement-related works (Tab. 20), concrete-related works (Tab. 21), and other works (Tab. 22) were determined.

TAB. 15: Work content of concrete-related works

TAB. 15: Work content of concrete-related works
\begin{tabular}{|l|c|c|c|c|}
\hline Activity & Scheme 1 & Scheme 2 & Scheme 3 & Scheme 4 \\
\hline Concreting for slab $\left(\mathrm{m}^{3}\right)$ (Zone A) & 44.39 & 69.61 & 54.80 & 48.32 \\
\hline Concreting for slab $\left(\mathrm{m}^{3}\right)$ (Zone B) & 40.05 & 14.83 & 29.64 & 36.12 \\
\hline Concreting for wall $\left(\mathrm{m}^{3}\right)($ Zone A) & 114.90 & 173.10 & 158.75 & 108.08 \\
\hline Concreting for wall $\left(\mathrm{m}^{3}\right)$ (Zone B) & 112.51 & 54.31 & 68.66 & 119.33 \\
\hline
\end{tabular}

TAB .16: Work content of reinforcement-related works

\begin{tabular}{|l|c|c|c|c|}
\hline Activity & Scheme 1 & Scheme 2 & Scheme 3 & Scheme 4 \\
\hline Slab connection reinforcement fixing (kg) (Zone A) & 480.00 & 483.23 & 521.14 & 531.63 \\
\hline Slab connection reinforcement fixing (kg) (Zone B) & 560.00 & 560.72 & 574.89 & 600.35 \\
\hline Slab reinforcement mesh fixing (kg) (Zone A) & 20.00 & 20.13 & 21.71 & 22.15 \\
\hline Slab reinforcement mesh fixing (kg) (Zone B) & 22.00 & 22.03 & 22.59 & 23.59 \\
\hline Wall reinforcement fixing (kg) (Zone A) & 10800.00 & 10872.60 & 11725.64 & 11961.65 \\
\hline Wall reinforcement fixing (kg) (Zone B) & 16200.00 & 16220.91 & 16630.81 & 17367.41 \\
\hline Wall reinforcement mesh fixing (kg) (Zone A) & 58.00 & 58.39 & 62.97 & 64.24 \\
\hline Wall reinforcement mesh fixing (kg) (Zone B) & 68.00 & 68.09 & 69.81 & 72.90 \\
\hline Delivery of reinforcement (kg) (Zone A) & 10800.00 & 10872.60 & 11725.64 & 11961.65 \\
\hline Delivery of reinforcement (kg) (Zone B) & 16200.00 & 16220.91 & 16630.81 & 17367.41 \\
\hline
\end{tabular}

TAB. 17: Work content of formwork-related works

\begin{tabular}{|l|c|c|c|c|}
\hline Activity & Scheme 1 & Scheme 2 & Scheme 3 & Scheme 4 \\
\hline Steel formwork installation $\left(\mathrm{m}^{2}\right)($ Zone A) & 666.62 & 1004.28 & 921.02 & 627.05 \\
\hline Steel formwork installation $\left(\mathrm{m}^{2}\right)$ (Zone B) & 1050.86 & 1583.15 & 641.29 & 1114.56 \\
\hline
\end{tabular}

TAB. 18: Work content of other works

\begin{tabular}{|l|c|c|c|c|}
\hline Activity & Scheme 1 & Scheme 2 & Scheme 3 & Scheme 4 \\
\hline Installation of façade (nr) (Zone A) & 13.00 & 21.00 & 16.00 & 16.00 \\
\hline Installation of façade (nr) (Zone B) & 13.00 & 5.00 & 10.00 & 10.00 \\
\hline Installation of electrical conduits (wall) (m) (Zone A) & 1059.68 & 1596.44 & 1464.09 & 996.78 \\
\hline Installation of electrical conduits (wall) (m) (Zone B) & 1319.00 & 636.70 & 804.93 & 1398.95 \\
\hline Steel formwork installation (m ${ }^{2}$ (Zone A) & 666.62 & 1004.28 & 921.02 & 627.05 \\
\hline Steel formwork installation $\left(\mathrm{m}^{2}\right)$ (Zone B) & 1050.86 & 1583.15 & 641.29 & 1114.56 \\
\hline
\end{tabular}


TAB. 19: Activity duration of concrete-related works

\begin{tabular}{|l|c|c|c|c|}
\hline Activity & Scheme 1 & Scheme 2 & Scheme 3 & Scheme 4 \\
\hline Concreting for slab (min) (Zone A) & 75.33 & 118.14 & 93.01 & 82.01 \\
\hline Concreting for slab (min) (Zone B) & 159.14 & 58.94 & 117.75 & 143.52 \\
\hline Concreting for wall (min) (Zone A) & 274.00 & 412.79 & 378.57 & 257.74 \\
\hline Concreting for wall (min) (Zone B) & 389.58 & 188.06 & 237.75 & 413.20 \\
\hline
\end{tabular}

TAB. 20: Activity duration of reinforcement-related works

\begin{tabular}{|c|c|c|c|c|}
\hline Activity & Scheme 1 & Scheme 2 & Scheme 3 & Scheme 4 \\
\hline Slab connection reinforcement fixing (min) (Zone A) & 75.46 & 75.97 & 81.93 & 83.58 \\
\hline Slab connection reinforcement fixing (min) (Zone B) & 113.07 & 113.22 & 116.08 & 121.22 \\
\hline Slab reinforcement mesh fixing (min) (Zone A) & 117.69 & 118.48 & 127.78 & 130.35 \\
\hline Slab reinforcement mesh fixing (min) (Zone B) & 175.29 & 175.51 & 179.95 & 187.92 \\
\hline Wall reinforcement fixing (min) (Zone A) & 381.70 & 384.27 & 414.42 & 422.76 \\
\hline Wall reinforcement fixing ( $\min )$ (Zone B) & 429.57 & 430.13 & 440.99 & 460.53 \\
\hline Wall reinforcement mesh fixing (min) (Zone A) & 105.31 & 106.02 & 114.33 & 116.63 \\
\hline Wall reinforcement mesh fixing (min) (Zone B) & 123.83 & 123.99 & 127.13 & 132.76 \\
\hline Delivery of reinforcement (min) (Zone A) & 40.33 & 40.60 & 43.79 & 44.67 \\
\hline Delivery of reinforcement (min) (Zone B) & 45.30 & 45.36 & 46.50 & 48.56 \\
\hline
\end{tabular}

TAB. 21: Activity duration of formwork-related works

\begin{tabular}{|l|c|c|c|c|}
\hline Activity & Scheme 1 & Scheme 2 & Scheme 3 & Scheme 4 \\
\hline Steel formwork installation (min) (Zone A) & 429.71 & 647.38 & 593.71 & 404.21 \\
\hline Steel formwork installation (min) (Zone B) & 426.92 & 643.17 & 260.53 & 452.80 \\
\hline
\end{tabular}

TAB. 22: Activity duration of other works

\begin{tabular}{|l|c|c|c|c|}
\hline Activity & Scheme 1 & Scheme 2 & Scheme 3 & Scheme 4 \\
\hline Installation of façade (min) (Zone A) & 80.79 & 136.20 & 103.63 & 102.59 \\
\hline Installation of façade (min) (Zone B) & 90.31 & 29.77 & 65.36 & 66.49 \\
\hline Installation of electrical conduits (wall) (min) (Zone A) & 273.64 & 412.25 & 378.08 & 257.40 \\
\hline Installation of electrical conduits (wall) (min) (Zone B) & 340.08 & 164.16 & 207.53 & 360.69 \\
\hline Steel formwork installation (min) (Zone A) & 429.71 & 647.38 & 593.71 & 404.21 \\
\hline Steel formwork installation (min) (Zone B) & 426.92 & 643.17 & 260.53 & 452.80 \\
\hline
\end{tabular}

\section{Daily working durations}

The results were shown in Fig. 8. On Day 1 and Day 4, the daily working durations for Scheme 2 and Scheme 3 are too long (more than 800 minutes) while the daily working durations in Scheme 1 and Scheme 4 are reasonable. On Day 2 and Day 5, the daily working durations of all schemes are similar. On Day 3 and Day 6, the daily working durations in Scheme 2 and Scheme 3 are shorter than those in Scheme 1 and Scheme 4. Nevertheless, Scheme 1 has the shortest fluctuations of daily working duration. Scheme 1 outperforms other schemes. 
TAB. 23: Daily working duration of four schemes

\begin{tabular}{|l|l|l|l|l|}
\hline Duration (min) & Scheme 1 & Scheme 2 & Scheme 3 & Scheme 4 \\
\hline Day 1 & 663.92 & 873.73 & 830.27 & 637.74 \\
\hline Day 2 & 704.91 & 637.25 & 692.19 & 771.56 \\
\hline Day 3 & 612.04 & 650.87 & 608.65 & 592.81 \\
\hline Day 4 & 739.34 & 763.64 & 821.01 & 849.38 \\
\hline Day 5 & 392.53 & 392.54 & 392.54 & 392.54 \\
\hline Day 6 & 474.38 & 316.08 & 340.22 & 504.67 \\
\hline Fluctuations & 137.96 & 162.09 & 182.95 & 227.62 \\
\hline
\end{tabular}

Daily duration of 6-day cycle

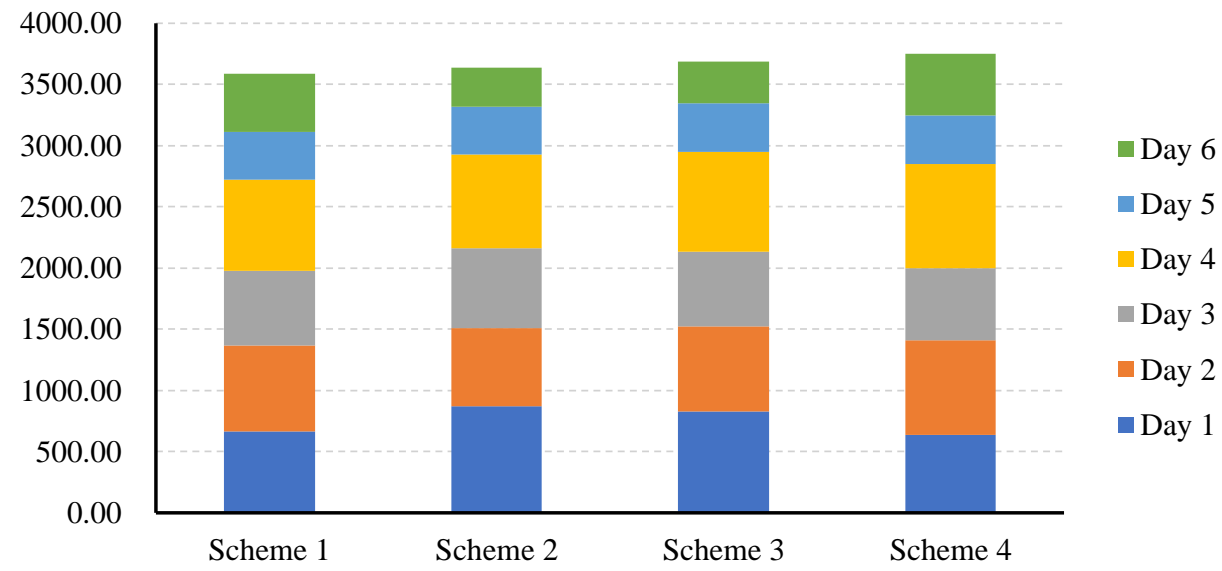

FIG. 8: Daily duration of 6-day cycle

\subsection{Heuristic rule 3: Utilisation rates of resources}

Based on the calculation result of resource utilisation in four schemes during 6-day cycle, the resource utilisation rate determined as shown in Tab. 24. The average utilisation rates as per Scheme 1, 2, 3, 4 are 25.84\%, 27.26\%, $26.11 \%, 25.89 \%$, respectively. The rankings of schemes in resource utilisation rates from high to low are Scheme 2, Scheme 3, Scheme 4, Scheme 1.

TAB. 24: Resource utilisation rates

\begin{tabular}{|l|c|c|c|c|}
\hline Average utilisation rates & Scheme 1 & Scheme 2 & Scheme 3 & Scheme 4 \\
\hline Concreter & $21.52 \%$ & $22.34 \%$ & $25.49 \%$ & $19.14 \%$ \\
\hline Labour & $21.52 \%$ & $22.34 \%$ & $25.49 \%$ & $19.14 \%$ \\
\hline Crane & $40.17 \%$ & $28.09 \%$ & $26.27 \%$ & $33.45 \%$ \\
\hline Crane operator & $40.17 \%$ & $28.09 \%$ & $26.27 \%$ & $33.45 \%$ \\
\hline Vibrator & $9.66 \%$ & $15.40 \%$ & $14.94 \%$ & $13.66 \%$ \\
\hline Bar bender & $23.42 \%$ & $22.56 \%$ & $25.77 \%$ & $26.47 \%$ \\
\hline Electrical fitter & $32.75 \%$ & $36.39 \%$ & $36.02 \%$ & $32.13 \%$ \\
\hline Form workers & $27.53 \%$ & $38.77 \%$ & $28.15 \%$ & $30.50 \%$ \\
\hline
\end{tabular}




\subsection{Selection of scheme of work-zone using proposed heuristic rules}

Tab. 25 shows the rankings of four work-zone definition schemes using the three proposed heuristic rules. In summary, Scheme 1 has the least length of the dividing line for work-zones; Scheme 1 and 4 perform better in daily duration; Scheme 1 and Scheme 2 perform better in resource utilisation. Scheme 2 and Scheme 3 with too long daily duration is not applicable in practice. As the resource utilisation rate of Scheme 1 and Scheme 4 is very close while the dividing length of Scheme 1 is much shorter than Scheme 4. As such, Scheme 1 is the best one among four schemes and deployed in practice.

TAB. 25: Rankings of four work-zone definition schemes by three proposed heuristic rules

\begin{tabular}{|l|c|c|c|c|}
\hline Rules & Scheme 1 & Scheme 2 & Scheme 3 & Scheme 4 \\
\hline Lengths of work-zone dividing lines & 1 & 2 & 3 & 4 \\
\hline Fluctuations of daily duration & 1 & $/$ & $/$ & 2 \\
\hline Utilisation rates of resources & 4 & 1 & 2 & 3 \\
\hline
\end{tabular}

\section{VALIDATION}

\subsection{Sensitivity analysis}

Sensitivity analysis is a technique used to determine how target outputs are affected based on changes in other input variables, thus validate the model reliability (Saltelli, 2002; Sargent et al., 2007). Sensitivity analysis was conducted to validate the models. The delay of duration for each activity is simulated to observe the impact on the duration of one 6-day cycle. Tab. 26 shows the delays of the activities. Put the set of different changes in the simulation model. The data of duration and resource utilisation is extracted and analysed. The result is shown in Tab. 27 and Tab. 28. Tab. 27 shows the duration of the 6-day cycle in this project as per the four schemes. The results show that the duration of the cycle increase as the delays incur. Similarly, Tab. 28 shows the resource utilisation rate. The resource utilisation rate reduced once the delay encountered. The results of sensitivity analysis are reasonable and thus the reliability of the models was verified.

TAB.26: Delays of activities for sensitivity analysis

\begin{tabular}{|c|c|c|}
\hline Activity & Duration (min) & Delay (min) \\
\hline Concreting for slab (Zone A) & 75.33 & +73.27 \\
\hline Concreting for slab (Zone B) & 159.14 & +28.09 \\
\hline Concreting for wall (Zone A) & 274.00 & +93.21 \\
\hline Concreting for wall (Zone B) & 389.58 & +92.48 \\
\hline Slab connection reinforcement fixing (Zone A) & 75.46 & +27.38 \\
\hline Slab connection reinforcement fixing (Zone B) & 113.07 & +142.47 \\
\hline Slab reinforcement mesh fixing (Zone A) & 117.69 & +154.94 \\
\hline Slab reinforcement mesh fixing (Zone B) & 175.29 & +69.50 \\
\hline Wall reinforcement fixing (Zone A) & 381.70 & +88.36 \\
\hline Wall reinforcement fixing (Zone B) & 429.57 & +63.41 \\
\hline Wall reinforcement mesh fixing (Zone A) & 105.31 & 0 \\
\hline Wall reinforcement mesh fixing (Zone B) & 123.83 & 0 \\
\hline Delivery of reinforcement (Zone A) & 40.33 & +46.20 \\
\hline +Delivery of reinforcement (Zone B) & 45.30 & +43.02 \\
\hline Steel formwork installation (Zone A) & 429.71 & +104.41 \\
\hline
\end{tabular}




\begin{tabular}{|l|c|c|}
\hline Activity & Duration (min) & Delay (min) \\
\hline Steel formwork installation (Zone B) & 426.92 & +25.21 \\
\hline Installation of façade (Zone A) & 80.79 & +17.01 \\
\hline Installation of façade (Zone B) & 90.31 & 0 \\
\hline Installation of electrical conduits (wall) (Zone A) & 273.64 & 23.06 \\
\hline Installation of electrical conduits (wall) (Zone B) & 340.08 \\
\hline Steel formwork installation (Zone A) & 429.71 \\
\hline Steel formwork installation (Zone B) & 426.92 \\
\hline
\end{tabular}

TAB. 27: Durations of one 6-day cycle for sensitivity analysis

\begin{tabular}{|l|c|c|c|c|}
\hline Schemes & Scheme 1 & Scheme 2 & Scheme 3 & Scheme 4 \\
\hline Duration (minutes) without delay & 3787.12 & 3634.11 & 3684.88 & 3748.70 \\
\hline Duration (minutes) with delay & 4273.81 & 4342.35 & 4244.36 & 4390.50 \\
\hline Response & +486.69 & +708.24 & +559.48 & +641.80 \\
\hline
\end{tabular}

TAB. 28: Resource utilisation of sensitivity analysis

\begin{tabular}{|l|c|c|c|c|}
\hline Schemes & Scheme 1 (\%) & Scheme 2 (\%) & Scheme 3 (\%) & Scheme 4 (\%) \\
\hline Without delay & 32.33 & 35.07 & 34.40 & 33.57 \\
\hline With delay & 25.84 & 27.26 & 26.11 & 25.89 \\
\hline Response & -6.49 & -7.81 & -8.29 & -7.68 \\
\hline
\end{tabular}

\subsection{Expert Evaluation}

The expert validation is testing whether the proposed method could achieve an acceptable level of performance by expert in related fields. In this research study, this proposed heuristic rules and the results were provided to a construction company in Hong Kong for expert validation. The focus group consists of a construction manager with over 30 years of experience, a site manager with over 15 years of experience, and a building engineer with 5 years of experience. They agreed that these three heuristic rules provide them with solid advice when choosing the best scheme for work-zone definitions. As such, the proposed rules were validated.

\section{WORK ZONE ANALYSIS WITH SMART FEATURE}

This study is closely related to the smart construction, smart cities, MiC and digitalisation. The proposed methods will be able to plan and control the work zone in building construction intelligently. Tab. 29 expresses the potential of smart applications of work zone analysis; and express the potential advantages and disadvantages when using work zone analysis with smart features.

Work zone analysis promotes smart construction (CIC, 2018) specifically for work planning and resource allocation. The technique is based on the use of digital technologies such as BIM technology and computer simulation. Work zone analysis at city level is innovative for smart city development (William and Robert, 2020). The proposed technique can be applied in multi-projects multi-sites scenarios. One site is equivalent to one workzone. The sub-contractor manages his own full-time skilled workers working in multiple sites in order to fully utilise the workers. Work zone analysis can be applied in Modular Integrated Construction (MiC) (Building Department, 2021). Material tracking system should be applied to track the delivery status such as the locations of industrial modules. The planned delivery time imposes the start time constraints of site installation activities. The module installation plan can be updated and adjusted by integrating the module delivery schedule in real time. 
Work zone analysis promotes digitalisation (Gray and Rumpe, 2015). The technique is based on the use of digital technologies such as BIM technology and computer simulation. Computer programming is required to automate work zone analysis.

TAB. 29: Work zone analysis with smart feature

\begin{tabular}{|c|c|c|c|}
\hline & $\begin{array}{l}\text { Smart applications of work zone } \\
\text { analysis }\end{array}$ & Advantages & Disadvantages \\
\hline Smart construction & $\begin{array}{l}\text { Work zone analysis promotes } \\
\text { smart construction, specifically } \\
\text { for work planning and resource } \\
\text { allocation. The technique is } \\
\text { based on the use of digital } \\
\text { technologies such as BIM } \\
\text { technology and computer } \\
\text { simulation. }\end{array}$ & $\begin{array}{l}\text { - Project duration can be reduced. } \\
\text { - Fluctuation of worker's daily } \\
\text { work hours can be minimised } \\
\text { across a week. } \\
\text { - Utilisation of project resources } \\
\text { can be improved from main } \\
\text { contractor's perspective. }\end{array}$ & $\begin{array}{l}\text { - Trainings should be provided to } \\
\text { equip project managers with the } \\
\text { knowledges of BIM technology } \\
\text { and computer simulation. }\end{array}$ \\
\hline Smart city & $\begin{array}{l}\text { - Work zone analysis at city level } \\
\text { is innovative for smart city } \\
\text { development. The proposed } \\
\text { technique can be applied in } \\
\text { multi-projects multi-sites } \\
\text { scenarios. One site is equivalent } \\
\text { to one work-zone. The sub- } \\
\text { contractor manages his own } \\
\text { full-time skilled workers } \\
\text { working in multiple sites in } \\
\text { order to fully utilise the } \\
\text { workers. }\end{array}$ & $\begin{array}{l}\text { Utilisation of company } \\
\text { resources can be improved from } \\
\text { sub-contractor's perspective. }\end{array}$ & $\begin{array}{l}\text { - Trainings should be provided to } \\
\text { equip project managers with the } \\
\text { knowledges of BIM technology } \\
\text { and computer simulation. }\end{array}$ \\
\hline $\mathrm{MiC}$ & $\begin{array}{l}\text { Work zone analysis can be } \\
\text { applied in MiC. Material } \\
\text { tracking system should be } \\
\text { applied to track the delivery } \\
\text { status such as the locations of } \\
\text { industrial modules. The planned } \\
\text { delivery time imposes the start } \\
\text { time constraints of starting site } \\
\text { installation activities. The } \\
\text { module installation plan can be } \\
\text { updated and adjusted by } \\
\text { integrating the module delivery } \\
\text { schedule in real time. }\end{array}$ & $\begin{array}{l}\text { - Project duration can be reduced. } \\
\text { - Utilisation of project resources } \\
\text { such as the carriers can be } \\
\text { improved from main } \\
\text { contractor's perspective. }\end{array}$ & $\begin{array}{l}\text { - Trainings should be provided to } \\
\text { equip project managers with the } \\
\text { knowledges of material tracking } \\
\text { system, BIM technology, and } \\
\text { computer simulation. }\end{array}$ \\
\hline Digitalisation & $\begin{array}{l}\text { Work zone analysis promotes } \\
\text { digitalisation. The technique is } \\
\text { based on the use of digital } \\
\text { technologies such as BIM } \\
\text { technology and computer } \\
\text { simulation. } \\
\text { programming is required to } \\
\text { automate work zone analysis. }\end{array}$ & $\begin{array}{l}\text { - Analysis will be fast and } \\
\text { accurate, depending on the } \\
\text { complexity of the construction } \\
\text { projects (e.g., BIM model, } \\
\text { simulation model). }\end{array}$ & $\begin{array}{l}\text { - Building information, such as } \\
\text { the details of reinforcement } \\
\text { bars, may not be easily } \\
\text { digitised. The sufficiency of } \\
\text { BIM information is highly } \\
\text { dependent on the level of details } \\
\text { of BIM models. }\end{array}$ \\
\hline
\end{tabular}

\section{LIMITATIONS OF WORK ZONE ANALYSIS}

The limitations of this research study are given as follow. The cost-benefit analysis was not considered. This research study has not used mathematical models to directly define the optimal work-zone dividing line. Three heuristic rules "lengths of dividing lines, fluctuations of daily durations, and resource utilisation rates" are used to evaluate work-zone definition schemes. Unified the units of the outcomes given by all the three rules required manual unit transformation by the project managers (e.g., the implied cost of the lengths of dividing lines, fluctuations of daily, and resource utilisation rates).

In addition, the success of using the proposed work zone analysis is dependent on the project size, project value, and project nature (whether the repetitive works can be identified). Tab. 10 shows the funding nature, project size, project value, project complexity, and project duration of building projects, civil/infrastructure projects, and industrial projects. Tab.11 shows the application of work zone analysis in building projects, civil/infrastructure 
projects, and industrial projects. In private housing projects, the work zone analysis can be applied for constructing typical floors such as residential flats and office units but not for constructing non-typical floors such as shopping mall. In civil/infrastructure projects (e.g., highway), the work zone analysis can be applied for performing repetitive works such as the works in a work section in highway, roadway, drainage, and tunneling projects. In industrial projects (e.g., oil-sands), however, the work zone analysis cannot be applied because no repetitive work can be identified in industrial projects.

TAB. 10: Funding nature, project size, project value, project complexity, and project duration of building projects, civil/infrastructure projects, and industrial projects

\begin{tabular}{|l|l|l|l|l|l|}
\hline Project type & Funding nature & Project size & Project value & Project complexity & Project duration \\
\hline Building project & Public housing project & $30 \mathrm{~m}^{2} / \mathrm{flat}$ & HKD \$1,063,100/flat & 36 typical floors & 33 months \\
\hline Building project & Private housing project & $40 \mathrm{~m}^{2} / \mathrm{flat}$ & HKD $\$ 1,200,300 / \mathrm{flat}$ & 36 typical floors & 40 months \\
\hline $\begin{array}{l}\text { Civil/Infrastructure } \\
\text { project }\end{array}$ & Public project & $7600 \mathrm{~m}^{2} / \mathrm{floor}$ & $\begin{array}{l}\text { HKD } \$ 506,000,000 / \\
\text { project }\end{array}$ & 29 months \\
\hline Industrial project & Private project & $2008.38 \mathrm{~m}^{2}$ & 1 & & 2 \\
\hline
\end{tabular}

TAB. 11: Application of work zone analysis in building projects, civil/infrastructure projects, and industrial projects

\begin{tabular}{|l|l|l|l|}
\hline Project type & Project funding nature & Application of work zone analysis & Examples \\
\hline Building project & Public housing project & Typical floor & Residential flat \\
\hline Building project & Private housing project & Typical floor & Residential flat \\
\hline Civil/Infrastructure project & Public project & Repetitive work sections & $\begin{array}{l}\text { Highway, roadway, drainage, and } \\
\text { tunnel }\end{array}$ \\
\hline Industrial project & Private project & Not identified yet & Not identified yet \\
\hline
\end{tabular}

\section{CONCLUSIONS}

In this research study, three heuristic rules were successfully discovered, standardised, and formalised. They are (i) lengths of work-zone dividing line, (ii) fluctuations of daily duration, and (iii) utilisation rates of resource. The work-zone scheme with shorter lengths of dividing lines, less fluctuations of daily duration, and higher utilisation rates of resource is preferred.

A case example was given to illustrate the steps of using the proposed rules. A project was successfully given by applying rules. There are two work-zone schemes: Scheme 1 (divided by "Line A-B") and Scheme 2 by (divided by "Line C-D"). The results were given as follows. Based on heuristic rule 1, "Line A-B" is shorter than "Line CD". Based on heuristic rule 2, the fluctuations of daily durations of Scheme 1 and Scheme 2 are 0.30 and 1.25 hours respectively. Scheme 1 is thus preferable. Based on heuristic rule 3, the average resource utilisation rates are $48.44 \%$ and $48.23 \%$ in Scheme 1 and Scheme 2 respectively. As such, Scheme 1 is chosen.

A practical case study was given to method application. The practical application of the proposed method is illustrated using a 40-storey building project. This project adapts 6-day construction cycle to construct 1 typical floor of a superstructure in 1 week. Four schemes of work-zone division were proposed. Three heuristic rules were applied to evaluate the four schemes. The results were given as follows. Based on heuristic rule 1, the lengths of dividing line are $1.55 \mathrm{~m}, 3.38 \mathrm{~m}, 38.30 \mathrm{~m}, 49.67 \mathrm{~m}$ for Schemes $1,2,3,4$, respectively. The rankings of scheme preference from the more preferable to less preferable are Scheme 1, 2, 3, 4. Based on heuristic rule 2, the fluctuations are 137.96min, 162.09min, 182.95min, 227.62min for Schemes 1, 2, 3, 4, respectively. The rankings of scheme preference from the more preferable to less preferable are Scheme 1, 2, 3, 4. Based on heuristic rule 3, the resource utilisation rates are re $25.84 \%, 27.26 \%, 26.11 \%, 25.89 \%$ for Schemes 1, 2, 3, 4, respectively. The 
rankings of scheme preference from the more preferable to less preferable are Scheme 2, 3, 4, 1. Based on results of three rules, Scheme 1 is chosen.

The academic contributions are given as follow. This research study is the first study to treat the construction process of a typical floor in 6-day cycle as repetitive work. This research study is the first study to focuses on the division of work-zone in building construction based on simulation techniques. This research study is the first study to improve the resource utilisation for construction project in 6-day cycle at workface level.

The practical contributions are given as follow. This research study provides the project manager with a standardised method to define better work-zone, so project managers would not only rely on their experience. This research study helps the project managers to arrange the works such that the daily working hours more reasonably by reducing fluctuation of daily duration. This research study enables higher resource utilisation rates by selecting better work-zone schemes.

The future research based on this research study can be to optimise proposed work-zone dividing lines using mathematical model, to automate the method for defining the work-zone line in consideration of the proposed heuristic rules, and to conduct detailed scheduling by constraints modelling at workface level.

\section{DATA AVAILABILITY STATEMENT}

All data generated or analysed during the study are included in the published paper.

\section{REFERENCES}

Agrama, F. A. (2014). Multi-objective genetic optimization for scheduling a multi-storey building. The International Conference on Civil and Architecture Engineering, 2014. Military Technical College, 1-21.

Agrama, F. A. (2015). Using spreadsheets features to schedule non-identical multi-storey building projects. 2015 International Conference on Industrial Engineering and Operations Management (IEOM), 2015. IEEE, 16.

Arditi, d., sikangwan, p. \& tokdemir, o. B. 2002. Scheduling system for high rise building construction. Construction Management \& Economics, 20, 353-364.

Bellman, R. (1966). Dynamic programming. Science, 153(3731), 34-37.

Biruk, S., and Rzepecki, L. (2019). Scheduling repetitive construction processes using the learning-forgetting theory. IOP Conference Series: Materials Science and Engineering, 2019. IOP Publishing, 112039.

Buildings Department. (2021). Modular Integrated Construction. Buildings Department, G/F, Buildings Department Headquarters, North Tower, West Kowloon Government Offices, 11 Hoi Ting Road, Yau Ma Tei, Kowloon, Hong Kong.

Cho, K., Hong, T., and Hyun, C. (2010). Integrated schedule and cost model for repetitive construction process. Journal of Management in Engineering, 26(2), 78-88.

Cho, K., Hong, T., and Hyun, C. (2011). Scheduling model for repetitive construction processes for high-rise buildings. Canadian Journal of Civil Engineering, 38(1), 36-48.

CLC (Construction Leadership Council). (2018) Smart Construction, A guide for housing clients. C/o Department for Business, Energy and Industrial Strategy, 1 Victoria Street, London.

Damci, A., Arditi, D., and Polat, G. (2013). Resource levelling in line-of-balance scheduling. Computer-Aided Civil and Infrastructure Engineering, 28(9), 679-692.

Devi, A. C., and Ananthanarayanan, K. (2007). A model for automated generation of resource-driven construction schedule for housing industry. 24th international symposium on automation and robotics in construction (ISARC, 2007), construction automation group, IIT Madras, 2007.

Dhanasekar, M. (2000). Identification of optimal size resources for a repetitive housing construction. Engineering Construction and Architectural Management, 7(4), 347-361. 
El-Rayes, K. (2001). Object-oriented model for repetitive construction scheduling. Journal of Construction Engineering and Management, 127(3), 199-205.

El-Rayes, K., and Moselhi, O. (2001). Optimising resource utilisation for repetitive construction projects. Journal of Construction Engineering and Management, 127(1), 18-27.

Gray, J. and Rumpe, B. (2015). Models for digitalisation. Software and Systems Modeling, 14(4), 1319-1320.

Hegazy, T., Abdel-Monem, M., and Saad, D. A. (2014). Framework for enhanced progress tracking and control of linear projects. Engineering, Construction and Architectural Management.

Hegazy, T., and Kamarah, E. (2008). Efficient repetitive scheduling for high-rise construction. Journal of Construction Engineering and Management, 134(4), 253-264.

Ho Song, M., \& Fischer, M. (2020). Empirical determination of the smallest batch sizes for daily planning. Journal of Construction Engineering and Management, 146(3), 04020011.

Ioannou, P. G., and Srisuwanrat, C. (2006). Sequence step algorithm for continuous resource utilization in probabilistic repetitive projects. Proceedings of the 2006 Winter Simulation Conference, 2006. IEEE, $1731-1740$

Jacobson, I. (1993). Object-oriented software engineering: a use case driven approach: Pearson Education India.

Leung, A. W., \& Tam, C. (2003). Scheduling for high-rise building construction using simulation techniques. CIB Report, 284, 186

Liu, H., Lu, M., \& Al-Hussein, M. (2014). BIM-based integrated framework for detailed cost estimation and schedule planning of construction projects. ISARC. Proceedings of the International Symposium on Automation and Robotics in Construction, 2014. IAARC Publications, 1.

Lopez del Puerto, C., and Gransberg, D.D., "Linear Scheduling for Production Home Building," 2010 Transactions, AACE, Int‘1, Atlanta, Georgia, June 2010, pp.PS.05.01-PS.05.08.

Lucko, G. (2009). Productivity scheduling method: Linear schedule analysis with singularity functions. Journal of Construction Engineering and Management, 135(4), 246-253.

Mitchell, M. (1998). An introduction to genetic algorithms: MIT press.

Rzepecki, Ł., and Biruk, S. (2018). Simulation method for scheduling linear construction projects using the learning-forgetting effect. MATEC Web of Conferences, 2018. EDP Sciences, 04007.

Saad, D. A., Masoud, M., and Osman, H. (2017). Lean scheduling of repetitive low income housing using cold formed steel. Leadership in Sustainable Infrastructure, 69, 1-10.

Sadeghi, N., Fayek, A. R., and Seresht, N. G. (2015). Queue performance measures in construction simulation models containing subjective uncertainty. Automation in Construction, 60, 1-11.

Sargent, Robert, 2007. Verification and validation of simulation models. Proceedings of the 39th conference on winter simulation, pp.124-137.

Saltelli, A. (2002). Sensitivity analysis for importance assessment. Risk analysis, 22(3), 579-590.

Shaheen, A. A., Fayek, A. R., and AbouRizk, S. M. (2009). Methodology for integrating fuzzy expert systems and discrete event simulation in construction engineering. Canadian Journal of Civil Engineering, 36(9), 14781490 .

Siu, M.-F. F., Lu, M., \& AbouRizk, S. (2016). Resource supply-demand matching scheduling approach for construction workface planning. Journal of Construction Engineering and Management, 142(1), 04015048.

Siu, M. F. (2016). Development of quantitative methods for project scheduling and workface planning under timedependent resource constraints. Doctor. Alberta

Srisuwanrat, C., Ioannou, P. G., and Tsimhoni, O. (2008). Simulation and optimization for construction repetitive projects using ProModel and SimRunner. 2008 Winter Simulation Conference, 2008. IEEE, 2402-2412. 
Su, Y., and Lucko, G. (2016). Linear scheduling with multiple crews based on line-of-balance and productivity scheduling method with singularity functions. Automation in Construction, 70, 38-50.

Suhail, S. A., \& Neale, R. H. (1994). CPM/LOB: New methodology to integrate CPM and line of balance. Journal of Construction Engineering and Management, 120(3), 667-684.

Tokdemir, O. B., Erol, H., and Dikmen, I. (2019). Delay risk assessment of repetitive construction projects using line-of-balance scheduling and Monte Carlo simulation. Journal of Construction Engineering and Management, 145(2), 04018132.

Tomar, A., and Bansal, V. (2019). Generation, visualisation, and evaluation schedule of repetitive construction projects using GIS. International Journal of Construction Management, 1-16.

Williams, S. (2020). "Defining Smart Cities: A Qualitative Study to Define the Smart City Paradox." Robert Morris University. ProQuest Dissertations Publishing, 2020. 27962171.

Yelle, L. E. (1979). The learning curve: Historical review and comprehensive survey. Decision sciences, 10(2), 302-328.

Zhang, L., Zou, X., and Kan, Z. (2014). Improved strategy for resource allocation in repetitive projects considering the learning effect. Journal of Construction Engineering and Management, 140(11), 04014053. 